\title{
Juan Ochoa: cantero de la iglesia de la Compañía de Jesús de Ayacucho (Perú)
}

\author{
Juan Ochoa: stonemason church of the Society of Jesus \\ of Ayacucho (Peru)
}

Raúl Hernán Mancilla Mantilla*

Doris Liliana Cconocc Flores ${ }^{* * *}$

\section{Resumen}

El artículo analiza el proceso constructivo del templo de la Compañía de Jesús de Ayacucho (Perú), edificado por el cantero Juan Ochoa Cárdenas a partir de 1645. Para desarrollar el estudio, hilvanamos en breves acápites; fundación de la ciudad, configuración urbanística y la fundación de la Compañía de Jesús en Huamanga. En los antecedentes de investigación, realizamos un balance historiográfico sumando nuestra contribución, amparada fundamentalmente mediante los documentos del concierto de fábrica, testamento y otros de Ochoa, hallados en el Archivo Regional de Ayacucho. Analizamos las características arquitectónicas y discutimos la filiación estilística del templo. Igualmente, contrastamos la arquitectura actual con la fuente documental del concierto. De igual forma, esbozamos algunos rasgos biográficos del cantero arequipeño.

\section{Palabras clave}

Ayacucho; Compañía de Jesús; Juan Ochoa; Colegios jesuíticos

\footnotetext{
* Artista Plástico por la Escuela Superior de Bellas Artes "Felipe Guamán Poma de Ayala” y Arqueólogo con estudios de maestría en Antropología.

*** Bachiller en Antropología en la Universidad Nacional de San Cristóbal de Huamanga.
} 


\begin{abstract}
The article analyzes the construction process of the temple of the Society of Jesus of Ayacucho (Peru), built by the mason Juan Ochoa Cardenas from 1645. To develop the study, hilvanamos in short sections; founding of the city, urban settings and the founding of the Society of Jesus in Huamanga. In the background research, we conducted a historiographical balance adding our contribution, mainly covered by the factory documents concert, will and other Ochoa found in the Regional Archive of Ayacucho. We analyze and discuss the architectural features of the temple stylistic affiliation. Similarly, contrast the current architecture with the concert documentary source. Similarly, we outline some biographical features of Arequipa stonemason.
\end{abstract}

\title{
Key-Words
}

Ayacucho; Society of Jesus; Juan Ochoa; Jesuit colleges

Recibido: 12 de diciembre de 2013

Evaluado: 19 de enero de 2014 


\section{Razones de la Fundación de San Juan de la Frontera de Huamanga.}

La ciudad de Huamanga se funda en el punto intermedio de las ciudades de Lima y Cusco, como defensa frente a las incursiones de Manco Inca y sus indios que andaban alzados desde la selva cusqueña y ayacuchana, y cuya fundación debía constituir: “...una ciudad de cristianos, para que hiciesen el paso seguro a los caminantes y contratantes, la cual se llamó San Juan de la Frontera...". San Juan de la Frontera de Huamanga, desde ese momento se va a constituir como centro militar y político en la colonia, más tarde por razones de la explotación del azogue de Huancavelica, cobra mayor lustre avecindándose muchos españoles en Huamanga.

La ciudad de San Juan de la Frontera de Huamanga tuvo dos fundaciones, la primera; el 29 de enero de 1539, y la segunda; el 25 de abril de 1540. Con respecto a la primera fundación existe controversias, lo señala Felipe Guaman Poma de Ayala, Raúl Rivera Serna al lugar de Quinua, mientras que Manuel Jesús del Pozo y Efraín Morote Best la zona de Huamanguilla. Lo cierto es que la primitiva sede, no tenía salidas en casos de guerra y los factores climáticos eran muy adversos que no permitían establecerse. Por estas razones deciden trasladarse a Pucaray el 25 de abril de 1540, (actual ciudad de Huamanga). Posteriormente, la denominación de San Juan de la Frontera va cambiar al de Victoria, debido al triunfo del Licenciado Cristóbal Vaca de Castro en la batalla de Chupas.

\section{Configuración urbanística de Huamanga.}

Por historia se sabe que las ciudades fundadas en el nuevo mundo, obedecían a patrones urbanísticos de las ciudades europeas del medioevo, con trazados renacentistas a través del sistema damero, de manzanas y calles rectas. El trazado de la ciudad de Huamanga a partir de la colonia como en otras ciudades responde a la mentalidad de cosmización, de fundar el universo frente al mundo profano llamado caos. "El caos estaba representado en aquel entonces por la presencia de mitimaes denominados Huancas, Andamarcas, Huancavilcas y otros. En este caso nos hallamos ante la superposición ideológica, imponiéndose el orden ante el desorden, la armonía ante el caos"². Una vez establecidos los españoles en Pucaray, este no era un lugar inhóspito, sino que estaba poblado por un conjunto de grupos étnicos mitimaes alrededor de un posible centro administrativo Inca, conforme se puede constatar en algunas evidencias arquitectónicas neoincas que aún perviven dentro de los inmuebles coloniales de la ciudad. La configuración urbanística de Huamanga colonial presenta características de arquitectura señorial de grandes portadas, con patios, arquerías, de uno a dos pisos, asimismo, destacaban las edificaciones de las órdenes religiosas. En la actualidad la ciudad de Huamanga, aún guarda su añeja presencia pese a la acelerada depredación de los defensores de un falso modernismo.

\footnotetext{
${ }^{1}$ Cieza, 1945: 233.

${ }^{2}$ Mancilla, 2005: 83.
} 


\section{La fundación de la Orden de la Compañía de Jesús en Huamanga.}

La Compañía de Jesús hace su aparición en el Perú en el año de 1568, y en Huamanga por abril de $1573^{3}$. Vásquez sostiene que los jesuitas hicieron presencia en Huamanga entre 1580 y 1590. Posteriormente, el Cabildo de Huamanga en 1605 le otorga licencia para la construcción del colegio, asignándole cuatro solares, es decir una manzana completa. Es muy probable, que en base a esta licencia fundaran su colegio el 15 de agosto de 1605, celebrándose una misa en la primitiva Capilla (Actual Escuela Superior de Música "Condorcunca").

Vásquez, detecta que los cuatro solares otorgados por el Cabildo no fueron suficientes para la edificación del colegio e iglesia, informando que: "Viendo los jesuitas que el terreno era insuficiente, comenzaron a comprar varias casas y solares colindantes, con la plata que recibieron del obispo; así adquirieron las casas de Antonio de Oré, por la suma de 8.100 pesos (1610); la de Antonio Delgadillo, su casa nombrada "puerta del diamante" situada en la esquina de la plaza mayor; de Diego Delgado, un solar, en la que se fabricó parte de la iglesia"4. Vásquez obvió citar la fuente, el cual nos hubiese facilitado analizar hasta qué punto fue cierta la donación de cuatro solares y la adquisición por compra venta de los inmuebles de la familia Oré, Delgadillo y Delgado. Entonces nos preguntamos ¿Qué pasó con la donación de los cuatro solares a los jesuitas por parte del Cabildo de Huamanga, o fue simplemente una propuesta? ¿Será posible que los cuatro solares donados por el Cabildo de Huamanga estuvieron ubicados en otra manzana adyacente? ¿Qué tipo de presiones habrían recibido las familias Oré, Delgadillo y Delgado para vender sus propiedades a los jesuitas? Esperamos en un estudio próximo esclarecer estas interrogantes.

Benoit $^{5}$, plantea que los jesuitas fueron los últimos en establecerse en la ciudad de Huamanga y con la creación del colegio en 1567, fomentaron un nuevo espíritu cultural en beneficio de la juventud huamanguina. Sobre la creación del colegio no cita la fuente, de ser cierto el año de 1567 , tendríamos que reconsiderar que 1605 , no es la fecha correcta de la fundación de los ignacianos en la ciudad de Huamanga.

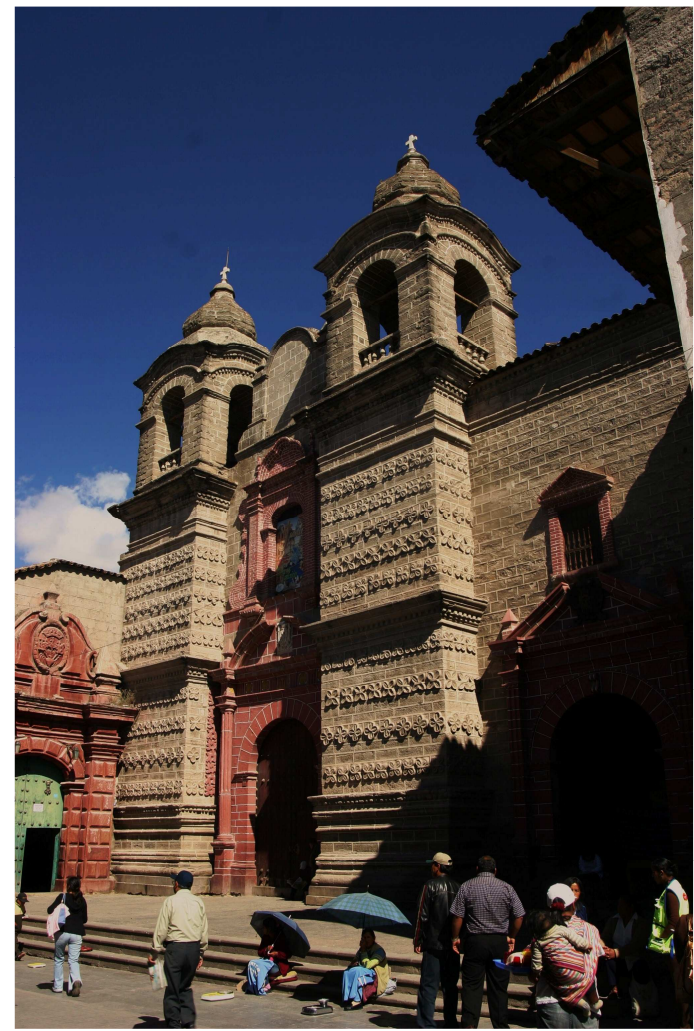

Iglesia del Colegio de la Compañía de Jesús en Ayacucho (Perú).

\footnotetext{
${ }^{3}$ Medina, 1942.

${ }^{4}$ Vásquez, 2011: 177.

${ }^{5}$ Benoit, 1947.
}

140 Raúl Hernán Mansilla Mantilla y Doris Liliana Cconocc Flores. Juan de Ochoa: catentero ... 
En cuanto a la fábrica del templo jesuítico en Huamanga, Vargas, plantea que la iglesia es posterior al año 1605, en que se hizo la fundación del Colegio. Diez años más tarde, se había terminado, por lo menos, la capilla de los indios, según se desprende del relato del P. Barrasa. Es muy probable que la edificación del templo se haya iniciado hacia el año 1628, colocándose la primera piedra por parte del señor obispo don Francisco Verdugo. "Unos diez y ocho años más tarde continuaban las labores porque en el año 1646 ó 1647 se envió a Huamanga al Hno. Nicolás de Villanueva, diestro cantero, para que ayudase en ellas. La bóveda se cerró en el año 1646 y en el año 1649 el templo estaba terminado, gracias a la actividad y acertada dirección del P. Rector, Francisco de Morales, arequipeño, que logró ver acabado en 1647 el cuerpo de la Iglesia, quedando solo por cubrir la capilla mayor. El P. Morales falleció el 6 de junio de 1648. Sus sucesores le dieron fin"”. El estudio de Vargas lo confirmamos con el hallazgo del concierto de fábrica de la iglesia nueva que data del 15 de marzo de 1645, firmado por el cantero Juan Ochoa y el P. Hernán de Aguilar, rector del colegio de la Compañía de Jesús. Posteriormente Wuffarden, en base al estudio realizado por Vargas, complementaría que el cantero arequipeño Juan Ochoa fue el artífice de la construcción de la iglesia nueva ${ }^{7}$.

\section{Antecedentes de investigación.}

Para abordar la investigación sobre la edificación del templo jesuita de Huamanga, recurrimos a las fuentes bibliográficas y hemerográficas que estuvieron a nuestro alcance. En base a estos referentes, esbozamos el derrotero del monumento jesuita. Entre los investigadores que contribuyeron, destacan: Pozo (1924), Medina (1942), Benoit (1947), Cossio (1958), Vargas (1963), Cortázar (1973), Blanco (1974), Riva Agüero (1974), Dammert et al., (1976), Velarde (1978), Sebastián et al., (1986), Mancilla (1989, 1990), González et al., (1996), San Cristóbal (1998), Wuffarden (2002) y Vásquez (2011).

Los estudios referentes a la arquitectura del templo están enfocados desde un punto de vista descriptivo y estilístico. Sin embargo, la generalidad de las publicaciones son breves aportaciones con ciertas excepciones, pero, carentes de investigaciones de fuentes documentales de archivos.

Pozo, al referirse a la iglesia de los jesuitas de Huamanga exalta la opinión del Dr. Luis Carranza, señalando que el arco carpanel: “...es una atrevida y grandiosa obra de

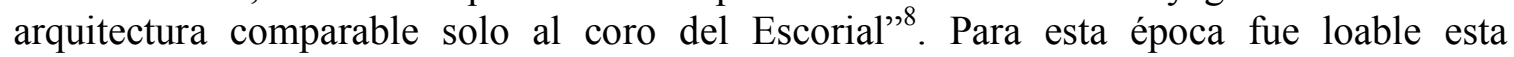
opinión, pero es una exageración, comparar dos monumentos diferentes en tiempo y espacio. En otro párrafo añade: "Esta atrevida obra de arquitectura, no es un arco, es una línea, que se curva ligeramente, en su extremidad longitudinal, lo que forma el mérito de esta parte de la iglesia de la Compañía, y que revela el talento de los padres jesuitas de la ciudad"9. Respetamos la apreciación del autor, pero debemos aclarar la ligera confusión que tuvo en su época, cuando señala “...no es un arco, es una línea..." en sí, se trata del arco carpanel en el lenguaje arquitectónico. Sobre este mismo elemento arquitectónico, Riva

\footnotetext{
${ }^{6}$ Vargas, 1963: 57.

${ }^{7}$ Wuffarden, 2002.

${ }^{8}$ Pozo, 1924: 66.

${ }^{9}$ Ibíd: 110.
}

141 Raúl Hernán Mansilla Mantilla y Doris Liliana Cconocc Flores. Juan de Ochoa: catentero ... 
Agüero expresa: "El coro alto tiene fama, por la audaz tensión de su arco"10. Su impresión es enfática. Igualmente, Medina resalta: "Ingresando al templo lo primero que llama la atención del visitante, es el indiscutible mérito arquitectónico del arco escarzonado del coro alto; obra en la cual se aunaron la audacia y la técnica del alarife que la proyectó y ejecutó" 11 . No cabe duda, que el arco carpanel está técnicamente logrado, de allí, el consenso de los estudiosos por valorar el legado que heredamos.

Benoit, en cuanto a la descripción del templo acota que "La fachada es de severa arquitectura jesuítica, con fuerte tendencia al barroco; se considera como uno de los más bellos templos de AYACUCHO. Llaman la atención los adornos en forma de alelíes que sobresalen de la fachada y las dos torres simétricas, hermosas y campanudas"12. Compartimos con Benoit la propuesta barroca en la fachada, empero, le faltó precisar algunos detalles que le hubiese dado más consistencia. A nuestro entender encontramos en el frontispicio del templo, una transición estilística del renacimiento al barroco. Las reminiscencias renacentistas se expresan en el diseño estructural y en los fustes estriados y el barroco por el frontón partido y por el movimiento de los entrantes y salientes de los muros.

Cossio sostiene que: "Sus pesados muros de piedra y ladrillo dan la sensación de solidez, de rudeza, desde la fachada donde el indígena ha querido mitigar el aspecto pesado, adornado con hileras de rosetas los paños alrededor de la entrada y las torres, llegando con su imprevisto bordado hasta los campanarios; efecto ornamental que nos transporta a los edificios chimús de la costa peruana y nos hace pasar por alto la imitación de rojos ladrillos entre las torres y el vano de la portada, fruto, sin duda, de alguna "intromisión" posterior que destruyó el efecto de la parte central" "13. Es evidente, que las estructuras arquitectónicas del templo son sólidas y para mitigar la rigidez de la fachada tuvieron que decorar con relieves de alhelís en los cuerpos de las torres. No compartimos con el autor cuando propone reminiscencias prehispánicas en la morfología decorativa de la fachada del templo, porque estas decoraciones de florones cuadrifoliados podrían corresponder quizás en parte a influencias del viejo mundo. Es cuanto a la intromisión posterior en el remate de la parte central de la iglesia es indiscutible, desde luego amerita un análisis arquitectónico.

Cortázar, plantea: "Las dos torres de ladrillo lucen frisos de flores esculpidas en los que lo críticos de arte han destacado la influencia arequipeña, notándose características propias en los campesinos" ${ }^{\prime 4}$. Cortázar comparte con los críticos de arte la influencia arequipeña en la fachada del templo, pero no los cita. Velarde, manifiesta: "La iglesia de la Compañía de Jesús ofrece igualmente aspectos de mucho interés. Sus torres de ladrillo, adornadas con fajas de flores esculpidas, de espíritu arequipeño, con sus remates de cornisas suaves y capulines de minarete, se destacan como curiosos ejemplos de campanarios" $^{\prime 15}$. Estos planteamientos estilísticos del barroco arequipeño propuestos por

\footnotetext{
${ }^{10}$ Riva Agüero, 1974: 72.

${ }^{11}$ Medina, 1942: 57.

12 Benoit, 1947: 23.

${ }^{13}$ Cossio, 1958:127.

${ }^{14}$ Cortázar, 1973: 38-39.

${ }^{15}$ Velarde, 1978: 303.
}

142 Raúl Hernán Mansilla Mantilla y Doris Liliana Cconocc Flores. Juan de Ochoa: catentero ... 
Cortázar y Velarde tienen sustento, porque el autor de este monumento es el cantero arequipeño Juan Ochoa de Cárdenas que: “...trabaja en esta iglesia de la Compañía de Jesús a partir del 15 de marzo de $1645^{\prime \prime 16}$.

Dammert et al., argumentan que la iglesia de la Compañía data del siglo XVII, y muestra una de las fachadas más interesantes de la arquitectura virreinal. Con respecto a las dos torres, proponen que son añadiduras del XVIII que rematan en capulines bulbosas, exhibiendo nueve filas horizontales de piezas de piedra compuesta de cuatro hojas que le dan un raro encanto ${ }^{17}$. El raro encanto de las hojas se refiere a los alhelís.

Tiempo después Sebastián et al., al referirse a las características de la portada del templo de la Compañía de Jesús, propone que: "La portada de la iglesia, cuyo antecedente es la de Santa Clara, está relacionada con el frontispicio que pone Serlio en su Libro VI. Los muros de la iglesia se decoran con florones cuadrifoliados, casi barrocos, en un ritmo que armoniza con la punta de diamante" ${ }^{\text {"18 }}$. En efecto, las dos portadas están emparentadas, pero edificadas en diferentes momentos. Cronológicamente, la fachada de Santa Clara data de 1568 y de la Compañía de Jesús de 1645. Es muy probable que el cantero Juan Ochoa artífice del templo de la Compañía haya tomado como modelo la portada del templo de Santa Clara y quizás haya conocido el libro de Serlio. Por otro lado, definen estilísticamente "casi barrocos" a los florones cuadrifoliados de los muros del templo, propuesta que consideramos acertada, que en voz alta podríamos denominarlo barroco andino.

Mancilla, da a conocer las primeras noticias sobre las obras realizadas por el maestro cantero Juan Ochoa de Cárdenas en la ciudad de Huamanga ${ }^{19}$. Por las investigaciones realizadas en las fuentes documentales del Archivo Regional de Ayacucho (ARAy), conocemos que la primera obra de gran envergadura que le encargaron a Juan Ochoa fue el claustro de Nuestra Señora de la Merced (1638), posteriormente la iglesia nueva de la Compañía de Jesús de Huamanga (1645).

Gonzáles, et al., (1996), esbozan brevemente la historia de los jesuitas en Huamanga, su fundación y describen las características arquitectónicas del templo. Definen que la portada es barroca y el cornisamento ondulado del campanario es típico del movimiento manierista ${ }^{20}$. Sobre la fachada barroca no hay nada que discutir, pero no compartimos con la propuesta del movimiento manierista, porque ésta no se ajusta a sus características, sino a las tendencias arquitectónicas de las torres mezquitas árabes.

San Cristóbal, comenta sobre un plano del colegio jesuítico de Ayacucho que se conserva en la Biblioteca Nacional de París, publicado por Santiago-Mesa-Gisbert. Plano que corresponde a la primera década del siglo XVII. Señala que esta iglesia carecía al menos durante la primera mitad del siglo XVII, de las torres gemelas que actualmente flanquean el muro de los pies. Supone con toda seguridad que se alzaría en el alto de los muros alguna espadaña renacentista. Concluye que la iglesia de la Compañía como en las

\footnotetext{
${ }^{16}$ Mancilla, 1989: 198.

${ }^{17}$ Dammert et al., 1976.

${ }^{18}$ Sebastián et al, 1986:35.

${ }^{19}$ Mancilla, 1989, 1990.

${ }^{20}$ Gonzáles, et al., 1996.
}

143 Raúl Hernán Mansilla Mantilla y Doris Liliana Cconocc Flores. Juan de Ochoa: catentero ... 
restantes iglesias menores ayacuchanas, se pasó del diseño renacentista de la fachada a los pies del diseño barroco introducido en el mismo lugar ${ }^{21}$.

El estudio de Wuffarden, constituye una de las más recientes investigaciones sobre la historia del templo y colegio jesuítico en Huamanga. Explica las transformaciones arquitectónicas que se produjeron en la edificación basándose en el plano antiguo que se conserva en dos copias en la Biblioteca Nacional de París. Originalmente, el templo constaba de una sola nave algo estrecha dispuesta en planta de cruz latina con brazos prolongados. Propone que debió labrase el cuerpo bajo de la portada principal, cuyo severo estilo renacentista difiere con la capilla primitiva anexa al lado derecho del atrio. A partir del 15 de marzo de 1645, el templo iniciaría una lenta reconversión bajo la dirección del alarife arequipeño Juan Ochoa de Cárdenas, y al año siguiente con apoyo del hermano Nicolás Villanueva, maestro cantero, concluirían las obras en 1649. Durante esta etapa se transforma la planta hasta desparecer el crucero y se añadieron los cubos de las torres. Sobre los cuerpos de las torres relucen relieves florales que le denomina a la fachada un aire decididamente arcaico. "En cambio, las formas ondulantes y bulbosas de los campanarios indican que fueron terminados en época tardía, quizá poco antes de la expulsión"22. El estudio de Wuffarden es una contribución valiosa y esclarecedora sobre las transformaciones arquitectónicas del templo. Además, es explícito en determinar el estilo renacentista de la portada del templo y expresar el arcaísmo de los resaltos de los relieves en los cubos de las torres. No compartimos con Wuffarden sobre las expresiones vertidas

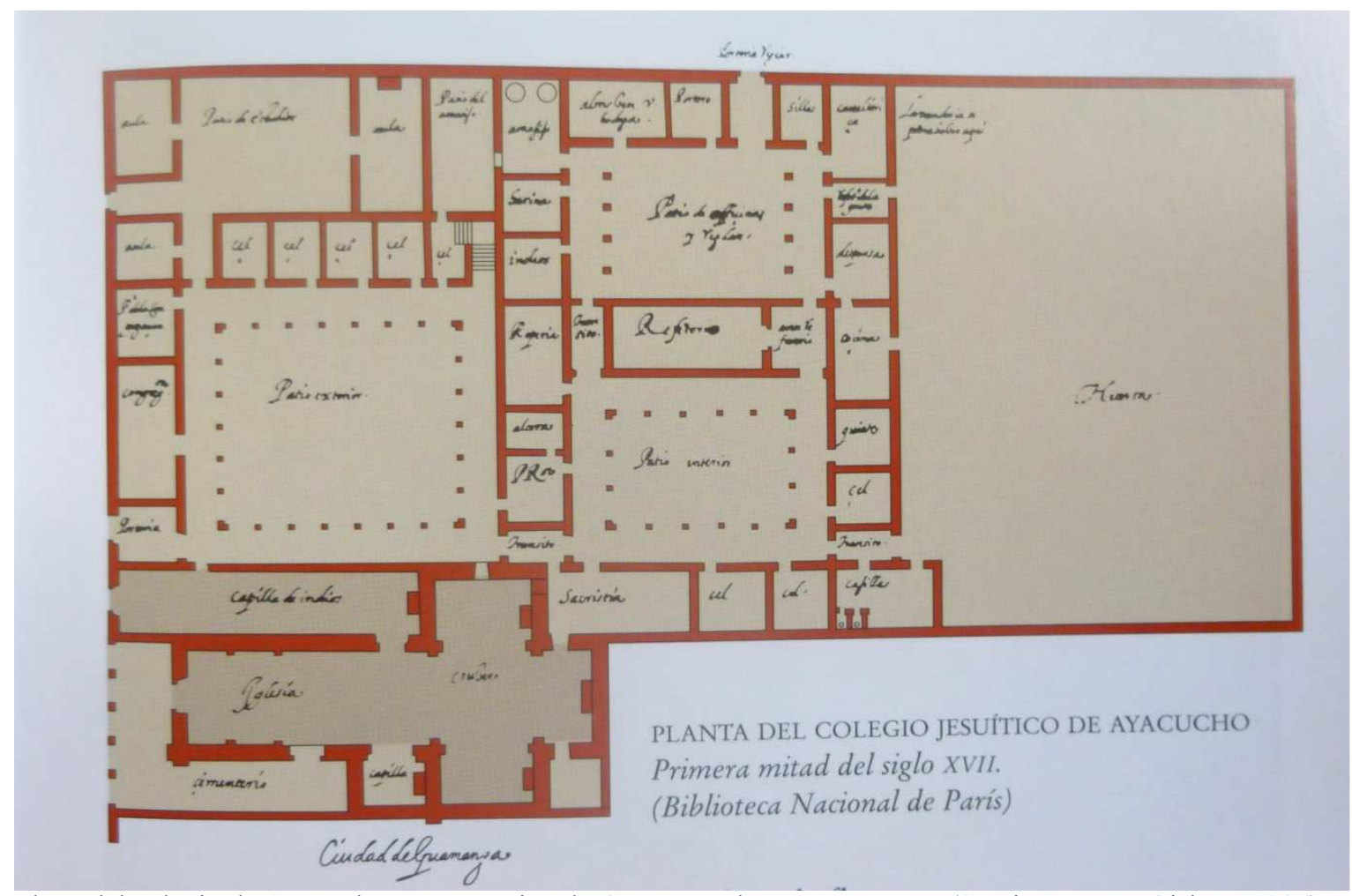

Plano del colegio de Ayacucho que se envió a la Compañía de Jesús en Roma (Santiago-Mesa-Gisbert, 1986).

\footnotetext{
${ }^{21}$ San Cristóbal, 1998.

${ }^{22}$ Wuffarden, 2002:164.
}

144 Raúl Hernán Mansilla Mantilla y Doris Liliana Cconocc Flores. Juan de Ochoa: catentero ... 
del arcaísmo en los cubos de las torres, porque de acuerdo a sus características éstas se ajustarían a la influencia del estilo barroco arequipeño conforme manifiestan Cortázar y Velarde.

\section{Ubicación}

El templo de la Compañía de Jesús se ubica aproximadamente a $50 \mathrm{~m}$, al suroeste de la Plaza Mayor de Ayacucho, colinda por el norte con la capilla de Loreto y la capilla primitiva actual local de la Escuela Superior Pública de Música "Condorcunca"; por el sur con la portada de ingreso a los claustros del colegio; por el este con el atrio y Jr. 28 de julio, y por el oeste con viviendas privadas.

\section{Descripción del templo}

La iglesia se erige sobre una plataforma elevada, destacando el alargamiento vertical del frontis en relación al ancho, a pesar de ello, mantiene una estrecha armonía proporcional con la capilla de Loreto, y la capilla primitiva. La puerta de ingreso presenta un arco de medio punto, flanqueado por fustes de reminiscencia renacentista apoyados sobre basamentos. Los fustes están acanalados a manera de estrías, con capiteles dóricos y no es de estilo compuesto como señala el mencionado Medina. Gonzáles, et al., propone que la portada es de estilo barroco. Superior a la puerta de ingreso destaca un friso con el escudo de los jesuitas y en sus extremos pares de relieves de flores dentro de un círculo, sobre ella un frontón semicircular partido. En el tímpano, reluce el escudo real de España, esculpida en piedra blanca en el año 1784. Sobre el frontón, se halla una pequeña portada con pilastras, vano con arco carpanel y un frontón trilobulado que enmarcan la ventana que da luz al coro. Remata la parte central de la portada en un gran frontón semicircular en cuyos extremos se alzan dos pináculos, a los lados, las dos torres. Los basamentos y cuerpos de las torres presentan resaltos decorativos labrados en piedra. En el primer cuerpo destacan cuatro filas de flores ornamentales, semejando alhelís en alto relieve, en el segundo cuerpo, sobresalen cinco filas de la misma decoración. Las torres se singularizan por tener capulines de minaretes.

La iglesia presenta una planta de cruz latina, de una sola nave, con bóveda de cañón corrido reforzada con arcos fajones, sin cúpula. En el interior sobresale el arco carpanel del coro alto y se comunica con la capilla de Loreto por una puerta de arco, con reja antigua de madera tallada, lado de la Epístola, y por el del Evangelio con la sacristía, compuesta de dos piezas amplias, una de ellas da acceso al púlpito y ambas al Colegio. La bóveda del altar de Jesús Nazareno y de la sacristía contigua tiene adornos en relieve. El techo es

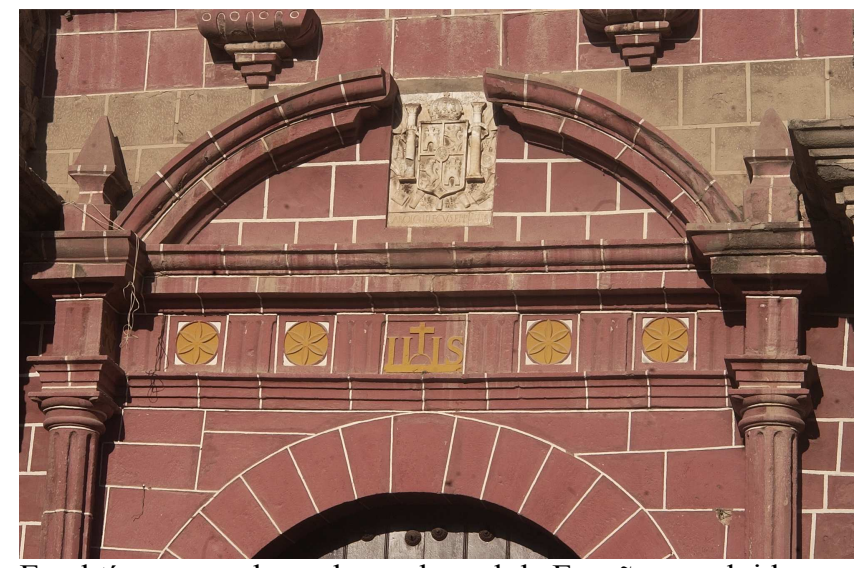

En el tímpano, reluce el escudo real de España, esculpida en piedra blanca en el año 1784 después de la expulsión de los jesuitas. 
de cal y piedra y en su parte exterior está cubierto con argamasa de cal y arena (Ver planos).

\section{Concierto entre Juan Ochoa y Hernán de Aguilar, rector de la Compañía de Jesús de Huamanga.}

Generalmente, los encargos solían suscribir ante un escribano de la ciudad con la finalidad de garantizar el cumplimiento de la obra. En este caso, formalizan el concierto de edificación del templo jesuita firmándose el 15 de marzo de 1645, entre el maestro cantero Juan Ochoa y Hernán de Aguilar, rector del colegio de la Compañía de Jesús de Huamanga.

Hasta la fecha en que se firma el concierto para edificar la iglesia nueva no existían indicios sobre la arquitectura antigua, sino se hubiese expresado en el documento. De allí, que el rector del colegio jesuita toma los servicios del experimentado cantero arequipeño Juan Ochoa, vecino y residente en Huamanga. En este concierto, Juan Ochoa se:

“... obligaba y obligó de hacer y labrar la iglesia nueva (que ante dicha Compañía de Jesús al presente se está fabricando), trabajando en ella por su propia persona en todo lo que fuere necesario de albañilería y cantería, desde mañana diez y seis deste presente mes y año en adelante y no alzar la mano della, continuamente haciendo todos los altares, y arcos, y arco toral, portada, bóvedas y coro y todo lo demás que necesariamente se hubiere de fabricar y hacer en la dicha iglesia, que así se obliga de hacer hasta que con exceso y perfección esté acabada de todo punto, sin dejarla de la mano ni soltar, continuamente ...,23.

Por el contenido del documento, se entiende que Juan Ochoa, en su condición de maestro cantero se compromete a edificar la iglesia nueva de la Compañía de Jesús, con sus altares, arcos, arco toral parada, bóvedas y coro. En la actualidad, el templo es de una sola nave con planta de cruz latina, bóveda de cañón corrido con arcos fajones, dos altares, ubicados en los lados laterales del crucero, coro alto y sotacoro de arco carpanel. Lamentablemente, no hallamos el plano arquitectónico anexado al concierto: asimismo, al contrastar el manuscrito con la arquitectura del templo, no encontramos el arco toral parada, probablemente se haya modificado en la ejecución de la obra, cuyas razones desconocemos.

Por otro lado el P. Hernán de Aguilar, rector del colegio de la Compañía de Jesús de Huamanga, se obliga a pagar al maestro cantero Juan Ochoa de Cárdenas por la fábrica del templo la suma de 300 pesos corrientes de a ocho reales, señalándose que:

“...le ha de dar e pagar el dicho padre rector o quien su causa hubiere, trecientos pesos corrientes de a ocho reales cada peso en esta manera: los ciento y cincuenta pesos dellos que el dicho padre rector le ha dado e pagado y ha recibido de él en reales de contado, de los cuales le dio por ante mí y entregados en su mano sobre que recibió la excepción de la // $f$. $226 \mathrm{v}$. / / innumerada pecunia y leyes de la

\footnotetext{
${ }^{23}$ ARAy. Prot. No 43. Leg. 33, f. 226r. 1644-1645.
} 
entrega ...ella de la paga (¿) Como en ellas junte y los otros ciento y cincuenta pesos de restantes cumplidos..., 24 .

Juan Ochoa recibe del P. Hernán de Aguilar un adelanto de 150 pesos de a ocho reales y al culminar recibiría los otros 150 pesos. Es evidente que la financiación de la fábrica del templo nuevo fue asumido por la Compañía de Jesús a través de su representante el P. Hernán de Aguilar rector del colegio jesuítico de Huamanga. Igualmente, el rector en otra de las condiciones del concierto:

“... se obligo de poner para la Dicha obra todos los peones y materiales necesarios para ella y de pagarles a su costa del Dicho colegio y de el pagar al dicho joanochoa los dichos ciento y cinquenta pesos de a ocho reales... "25.

La obligación asumida por el rector de apoyar al maestro Juan Ochoa con todos los peones y materiales para la fábrica de la iglesia, es una manera de garantizar el cumplimiento del proyecto. También, significó abaratar la dirección técnica, porque 300 pesos no justificaría un proyecto de esta naturaleza, ya que anteriormente había cobrado 4.100 pesos por la fábrica del claustro mercedario. No entendemos por qué razones Juan Ochoa tuvo que cobrar solo 300 pesos o quiso dejar testimonio de su arte en esta región. Finalmente, en el documento especifican las penalidades en caso de incumplimiento o por no estar de acuerdo al diseño.

\section{Juan Ochoa: noticia biográfica.}

En esta oportunidad intentaremos perfilar algunos aspectos de la vida y la obra del maestro cantero Juan Ochoa de Cárdenas, en base a los manuscritos descubiertos en el Archivo Regional de Ayacucho (ARAy). Las informaciones referentes a Juan Ochoa, provienen de la sección de protocolos y de los rubros: conciertos, venta, testamento, asiento de aprendiz y obligación. Por el momento la documentación más temprana data de 1638 y el último de 1645, aunque podemos tener sorpresas en el transcurso de la investigación. Con este corto período de siete años de Juan en Huamanga, trataremos de conocer algunas de sus actividades.

Los compromisos adquiridos por el cantero arequipeño Juan Ochoa durante sus siete años de permanencia en Huamanga, están historiadas: Primero: concierto de fábrica del claustro de Nuestra Señora de la Merced, de 1638. Segundo: venta de mulas, de 1638. Tercero: testamento de 1642. Cuarto: asiento de aprendiz de 1643. Quinto: concierto de fábrica del templo de la Compañía de Jesús de Huamanga de 1645. Y Sexto: obligación para culminar el claustro mercedario en 1645.

Para tener una visión panorámica sobre la vida de Juan Ochoa, iniciaremos analizando su testamento, alternado simultáneamente con los otros manuscritos de manera cronológica. El testamento data del 16 de junio de 1642, firmado en Huamanga, ante el

\footnotetext{
${ }^{24}$ Ibíd. f. 226r - 226v.

${ }^{25}$ Ibíd., f. 226v.
} 
escribano público Francisco de Peñaranda y en presencia de cinco testigos. En este documento expresa: "Yten declaro que soi natural de la ciudad de arequipa hixo de Juan Ochoa alvañil y de doña catalina de cardenas difuntos declarolo para que conste"

Con la presente declaración testimonial, se confirma que Juan es natural de la ciudad de Arequipa e hijo del albañil Juan Ochoa y de doña Catalina de Cárdenas. En el documento no se hace mención sobre la fecha de nacimiento, ya que al parecer los escribanos públicos no tenían costumbre de anotar este tipo de datos, el cual nos hubiese permitido tener mayor precisión sobre el artista. Empero, es posible que haya nacido hacia fines del siglo XVI o a comienzos del siglo XVII.

Por otro lado, la confesión de Juan nos proporcionó una valiosa información sobre la actividad de su señor padre, quien había ejercido la profesión de albañil. En el proceso de la presente investigación tuvimos la suerte de encontrar en la publicación de Vargas (1968), noticias sobre el maestro albañil Juan Ochoa, conocido e importante alarife que realizó “... en 1614 ciertas obras, corredores y arquerías, en la casa de Cabildo de Arequipa y cuatro tiendas, con Diego cabrera, procurador del mismo" ${ }^{, 27}$.

El mismo hecho de encargar el proyecto a Juan Ochoa (padre) ciertas obras del cabildo de Arequipa, confirmaría su alto nivel profesional. Por el cruce de estas fuentes documentales, nos atrevemos a sostener que el maestro albañil, autor de los corredores y arquerías del Cabildo de Arequipa, fue padre de nuestro biografiado. Contrastando el testamento de Juan, con la noticia de Vargas, encontramos una correlación lógica; primero: con el apellido, segundo: con la ciudad y tercero: con la profesión.

El despertar artístico de Juan (hijo), debió iniciarse en la ciudad de Arequipa, formado por su padre de oficio albañil. El influjo del padre fue determinante en la vocación artística del hijo, que trabajaría en el arte de cantería desde su ciudad natal. Desconocemos hasta la presente investigación la fecha de arribo a Huamanga, probablemente habría sido llamado por la Orden Mercedaria, para realizar la fábrica del convento en el año 1638, por su maestría en el arte de arquitectura. Otra posibilidad es que estaría ya afincado en esta ciudad, habiendo realizado quizás obras civiles y religiosas, pendiente aún por descubrirse en los fondos documentales del ARAy.

Igualmente, en su testamento declaró estar casado católicamente por la iglesia con Juana Barrientos y en dicho matrimonio no tuvieron hijos. De la misma forma, expresó que estuvo separado desde hace buen tiempo atrás, conforme manifiesta:

"Yten declaro que soi casado conforme orden de la Santa madre Yglesia con Juana Varrientos ya muchos años que no ago vida con ella ni e tenido en este matrimonio hixos ningunos declarolo para que conste.

Yten declaro que no tengo herederos ascendientes ni decendientes legitimos ni forsosos declarolo para que conste ${ }^{, 28}$.

\footnotetext{
${ }^{26}$ Ibíd., Prot. No 53. Leg. No 43. f. 51r. 1642-1644.

${ }^{27}$ Vargas, 1968: 294.

${ }^{28}$ ARAy; Prot. $N^{\circ}$ 53. Leg. No 43. f. 51r. 1642-1644.
} 
No obstante, es probable que Juan Ochoa haya contraído matrimonio en la ciudad de Huamanga, antes de 1638 o posterior al citado año. De igual manera, desconocemos las razones de separación, porque no se precisa en el testamento y tampoco tuvo herederos.

Hasta este punto llegamos en conocer parte de vida, y para examinar las obras plasmadas por Juan en Huamanga analizaremos retrospectivamente los manuscritos previos al testamento de 1642. La primera noticia documentada está referida al concierto de fábrica del claustro de la Orden de Nuestra Señora de la Merced de Huamanga. Concierto firmado el 22 de abril de 1638, entre el maestro cantero y los frailes mercedarios. En este compromiso, se estipularon las características arquitectónicas del claustro, el monto económico que importaba la fábrica y la fecha de entrega.

Transcurrido 25 días de haber firmado el concierto del claustro mercedario, descubrimos otro documento del 17 de junio de 1638: referido esta vez a la "venta de mulas". En esta ocasión Juan Ochoa y Miguel Heredia, compran cuatro mulas del señor Antonio Pereira, pagando por cada una de las mulas, la suma de 37 pesos y medio de a ocho reales. En este documento, los compradores acordaron pagarle en dos armadas y dentro de 45 días.

Juan Ochoa, en el concierto del 22 de abril de 1638, expresó entregar el claustro concluido para el mes de abril de 1639. Lamentablemente, no llegó a cumplir porque su fiador el presbítero Andrés de Talamanca, falleció teniendo en su poder los 3.100 pesos de a ocho reales. Sin embargo, hasta el año de 1642 en que firma su testamento, habían acontecido cuatro años y la fábrica del claustro se hallaba inconclusa. De allí, que en su testamento exponga:

"Primeramente declaro que avra quatro años Poco mas o menos que tome el aser los claustros de el convento de nuestra señora de las mercedes Y la ovra a ellos accesoria en compañía del Licenciado andres de talamanca y me obligue de que en Vn año acavaria la dicha ovra Y a tardado quatro años por no aver acudido el dicho andres de Talamanca a lo que estava ovligado Como Paresera por escritura $Y$ reciuimos quatro// $f$. $49 \mathrm{r}$. //mill Y sien pesos de a ocho reales deviendo los tres mill Y sien pesos el dicho andres de talamanca Y los mill Restantes los resivi en Dos esclavos nombrados Pedro Angola Y Lucas Criollo el cual mate (ilegible) en mi poder vn esclauo del dicho andres de talamanca Por aver espirado el dicho concierto por su muerte...",29.

Hasta este punto quedan claras y justificadas, las razones del porqué el cantero Juan Ochoa, no pudo concluir el claustro mercedario, cuya causa se debió a la muerte de su fiador el presbítero Andrés de Talamanca, quien poseía los 3.100 pesos de a ocho reales, pese a que los albaceas debieron asumir con la responsabilidad. Además, hace constar haber recibido dos esclavos negros como parte de los mil pesos. Para dar solución al caso, propone en su testamento, que el claustro se culmine conforme a su obligación, trayendo a cuenta de sus bienes un maestro cantero, o en caso contrario, se valorice lo que quedó pendiente y se pague de sus bienes hasta que la deuda quede satisfecha.

${ }^{29}$ Ibíd. f. 48v., 49r. 1642-1644.

149 Raúl Hernán Mansilla Mantilla y Doris Liliana Cconocc Flores. Juan de Ochoa: catentero ... 
El 21 de abril de 1643, posterior al testamento, localizamos el documento de "asiento de aprendiz". En esta ocasión, el maestro Ochoa recibe por aprendiz al mancebo Antonio López Vosa, comprometiéndose enseñar el oficio de cantero al aprendiz Antonio López, por un período de 2 años. Por el manuscrito de asiento de aprendiz, se confirma que no fallece de la enfermedad que padecía. Por este acontecer, su testamento quedó asentado ante el escribano como simple escrito. Es muy probable que su verdadero testamento sea post 1645 y nos preguntamos ¿Habrá fallecido en Huamanga, en Arequipa o en otra ciudad?, solo las investigaciones de fuentes documentales nos podrán confirmar.

El compromiso más relevante que asume del cantero Juan Ochoa, fue realizar la iglesia nueva para la orden de la Compañía de Jesús de Huamanga. En este concierto del 15 de marzo de 1645, el rector del Colegio de la Compañía de Jesús de Huamanga, se compromete pagar a Juan Ochoa la suma de 300 pesos de a ocho reales por la ejecución de la obra. Creemos que Juan Ochoa con esta obra arquitectónica, se consagre definitivamente como introductor del estilo barroco arequipeño en la ciudad de Huamanga. Con justa razón proponían Velarde (1978) y Cortázar (1973) en atribuir el frontis del templo jesuita de espíritu arequipeño, en el cual acertaron estilísticamente y lo corroboramos por la declaración de su testamento donde manifestó ser natural de la ciudad de Arequipa.

Posteriormente, el 24 de abril de 1645 descubrimos el último documento de "obligación" firmado entre Juan Ochoa y el padre fray Jacinto Galindo, Visitador General del convento de Nuestra Señora de la Merced para culminar la fábrica del claustro pendiente desde el año 1638. En este documento, Juan se compromete labrar 160 piedras de cantería a su costa, sin que el convento tenga obligación de darle cosa alguna para él ni los jornales de los negros. Merece tomar en cuenta la presencia de negros como Pedro Angola y Lucas Criollo en el taller del maestro cantero, que participaron en acabar el claustro mercedario. Juan en este documento se obliga a entregar el claustro para fines del mes de julio o para comienzos de agosto de 1645 .

Por los encargos asumidos por Juan Ochoa en la fábrica del claustro mercedario y de la iglesia nueva del Colegio de la Compañía de Jesús de Huamanga, podemos destacar que fue un alarife de primer nivel y con vasta experiencia. Es muy probable que el arte de Juan haya tenido seguidores, pero no estamos seguros de referirnos sobre una escuela de canteros en Huamanga. Esperamos en un futuro próximo conocer otras actividades realizadas por Juan Ochoa en Ayacucho. 

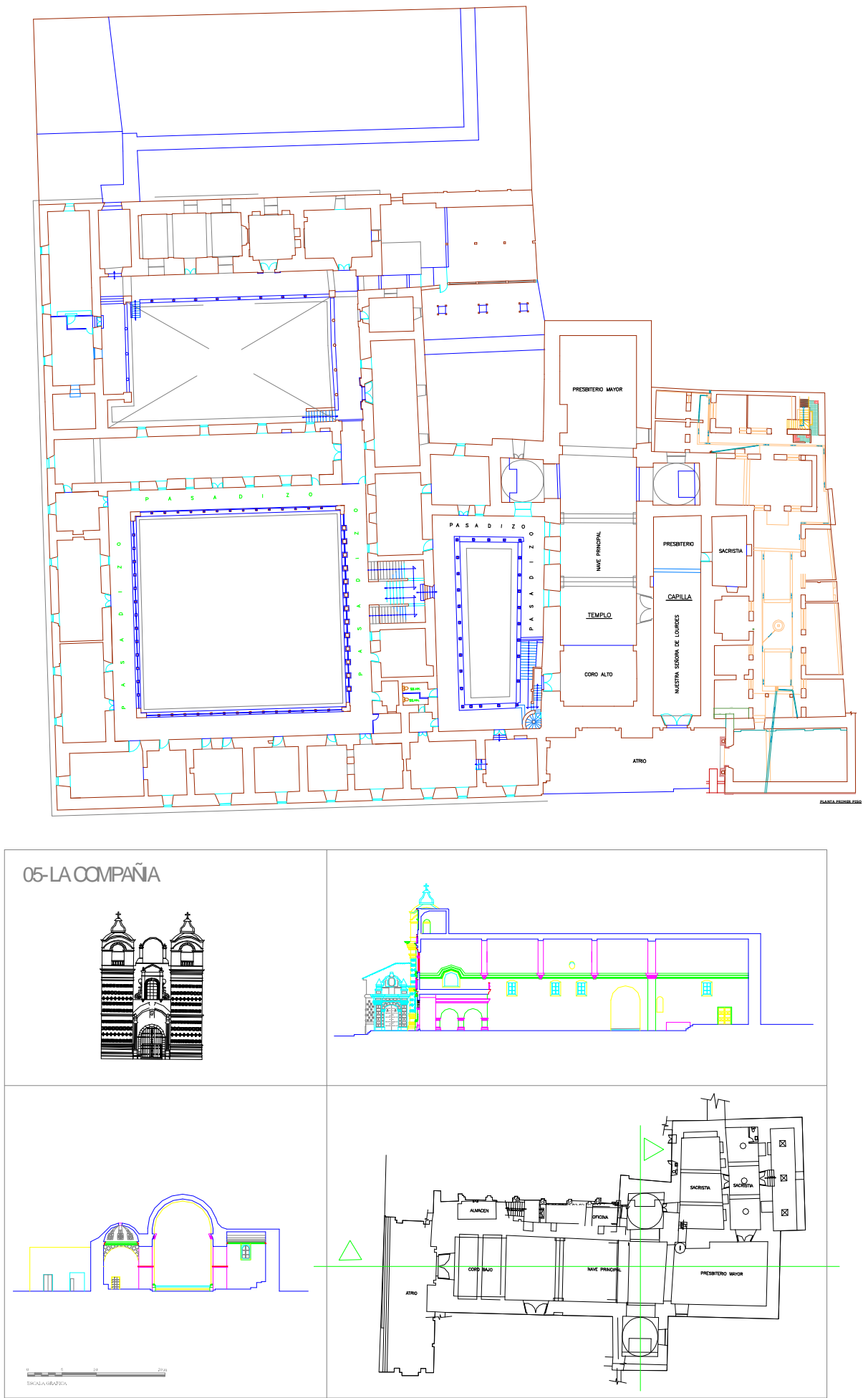

PLANO: Conjunto arquitectónico de la Compañía de Jesús de Ayacucho. Cortesía: Agencia Española de Cooperación Internacional. 
IHS. Antiguos jesuitas en Iberoamérica ISSN: 2314-3908

vol. 1 no 2

2013

\section{Apéndice documental}

\section{CONCIERTO DE FÁBRICA DEL TEMPLO DE LA COMPAÑÍA DE JESUS DE AYACUCHO.}

\section{// f. 226 r.// Concierto entre Joan Ochoa cantero y el padre Hernán de Aguilar de la Compañía de Jesús (Al margen).}

En la ciudad de Huamanga del Perú, en quince días del mes de marzo del año de mil seiscientos y cuarenta y cinco, ante mí el escribano público y de cabildo y testigos... [se presentaron] Joan Ochoa maestro cantero, vecino morador desta dicha ciudad de la una parte y, de la otra, el padre Hernán de Aguilar, rector del colegio de la Compañía de Jesús desta dicha ciudad, a los cuales doy fe que conozco y otorgaron que eran convenidos y concertados en esta manera: que el dicho Joan Ochoa se obligaba y obligó de hacer y labrar la iglesia nueva (que ante dicha Compañía de Jesús al presente se está fabricando), trabajando en ella por su propia persona en todo lo que fuere necesario de albañilería y cantería, desde mañana diez y seis deste presente mes y año en adelante y no alzar la mano della, continuamente haciendo todos los altares, y arcos, y arco toral, portada, bóvedas y coro y todo lo demás que necesariamente se hubiere de fabricar y hacer en la dicha iglesia, que así se obliga de hacer hasta que con exceso y perfección esté acabada de todo punto, sin dejarla de la mano ni soltar, continuamente deba, por razón de lo cual le ha de dar e pagar el dicho padre rector o quien su causa hubiere, trecientos pesos corrientes de a ocho reales cada peso en esta manera: los ciento y cincuenta pesos dellos que el dicho padre rector le ha dado e pagado y ha recibido de él en reales de contado, de los cuales le dio por ante mí y entregados en su mano sobre que recibió la excepción de la // f. $226 \mathrm{v}$. / / innumerada pecunia y leyes de la entrega por ella de la paga (i) Como en ellas junte y los otros ciento y cincuenta pesos de restantes cumplidos ................La Dicha comunidad que Le han de pagar luego que entregara (i) y acabado como dicho es La Dicha obra yglesia (i) y se obliga (de no gastar) $(i)$ de la Dicha obra........................hasta $(i)$ que se gastare algunDia..........................Vno de los que gastare $(i)$ se Leo y han de descontar dos pesos de a ocho reales La berificase esta $(i)$ y prueba $(i)$ dello $(i)$ y (de fines)(i) obre e juramento simple Del dicho padre rector o de quien su causa (obrasen) (i) de (i) otra (i) prueba (¿) De que el rector.......................presente El dicho padre rector Hernán de AguiLar otorgo que .................. aser obra escriptura En su ........................ y como En ella se ...........................y se obligo de poner para la Dicha obra todos los peones y materiales necesarios para ella y de pagarles a su costa del Dicho colegio y de el pagar al dicho joanochoa los dichos ciento y cinquenta pesos de a ocho reales al ...............devia (i) no (i) entra $(\dot{i})$ al ...............y denle dichos....................pena (i) de el pagar por (i) entero (i) Como si Ubiera hecho toda la dicha iglesia Como dicho (le como asi los) (¿) Daños e yntereses que se le siguiera resolvieran $(i)$ y les $(i) \ldots \ldots \ldots \ldots \ldots \ldots \ldots \ldots \ldots \ldots \ldots$ de la cobranza y al cumplimiento $(i) \ldots \ldots \ldots \ldots$ al $(i)$ paga $(i)$ de lo que de $(i)$ dejarla $(i) \ldots \ldots \ldots \ldots$ que le toca obligaciones (i) de joanochoa su persona bienes y es dicho e (i) resoluciones $(i)$ rector del dicho colejio.............por $(i) \ldots \ldots \ldots \ldots \ldots \ldots \ldots \ldots \ldots \ldots$ ambos dieren todo cumplido a cualesquier (jueses) (¿) y fueros (¿) de Su majestad y eclesiasticos que de sus Causas puedo 
(¿) y deban conocer a quien se sometieran con relacion (¿) De su fuero y la lei que dije que le acordase (i) su fuero (i) el fuero de

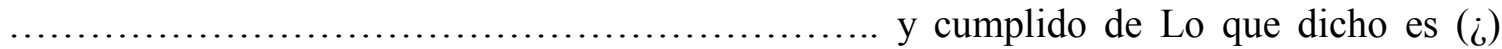
Como personas $(i) \ldots \ldots \ldots \ldots \ldots \ldots \ldots \ldots$ por $(i)$ fiansa $(i)$ firmado $(i)$ pasado $(i) \ldots \ldots \ldots \ldots \ldots \ldots \ldots \ldots$ y renunciasen (i) $\ldots \ldots \ldots \ldots \ldots \ldots$ desde $(i)$ su (i) qualesprohibe otorgaren y firmaron de su

Juan Ochoa (Rúbrica) Hernán de Aguilar (Rúbrica).

Ante my de testigo (?) de su majestad (?)

Joan Falcon del Valle (Rúbrica).

Escribano Público de cabildo (?)

\section{Referencias}

\section{Archivos}

ARAy. Archivo Regional de Ayacucho (ARAy)

\section{Bibliografía}

Benit, Luis (1947). Viajes por el Perú Centro y Sur, Lima: Editorial P.T.C.M.

Blanco, José M. (1974). Diario del viaje del Presidente Orbegoso al sur del Perú, Lima: Pontificia Universidad Católica del Perú. Instituto Riva Agüero.

Cieza de León, Pedro (1945). La crónica del Perú, Argentina.

Cortázar, Pedro F. (1973). Documental del Perú. Departamento de Ayacucho. Lima: Ioppe S.A. Quinta Edición. Lima. Volumen IV- Abril.

Cossio del Pomar, Felipe (1958). Arte del Perú colonial. México-Buenos Aires.

Dammert León, Augusto, Cusman Cárdenas, Tulio (1976). Ayacucho la Libertad de América. Lima.

González, E.; Levano, J. y Urrutia, J. Ayacucho. San Juan de la Frontera de Huamanga. Lima: Banco de Crédito del Perú.

Mancilla Mantilla, Raúl H. (1989). "El retablo mayor de la Compañía de Jesús de Ayacucho y el taller de ensambladores en la primera década del siglo XVIII". En: Boletín del Riva-Agüero. $\mathrm{N}^{\circ}$ 16. Lima: Pontificia Universidad Católica del Perú. (1990). Investigación de arqueología - histórica: arquitectura del convento de la Merced de Ayacucho. Tesis para Optar Grado de Bachiller en Arqueología. Universidad Nacional de "San Cristóbal" de Huamanga. Facultad de Ciencias Sociales. Escuela Profesional de Arqueología e Historia. Ayacucho. - (2005). "El proceso simbólico del centro histórico de la ciudad de Ayacucho. En: Itinerarios del Proceso Urbano: Ayacucho en la perspectiva de la antropología urbana. Huancayo.

Medina, Pio Max (1942). Monumentos coloniales de Huamanga. Ayacucho.

Pozo, Manuel J. del. (1924). Historia de Huamanga. (Epoca colonial). Ayacucho. 
Riva Agüero, José de la (1974). Paisajes peruanos. Biblioteca peruana (Peisa), Lima.

San Cristóbal, Antonio (1998). Esplendor del barroco en Ayacucho. Retablos y arquitectura religiosa en Huamanga. Lima: Banco Latino.

Sebastián, Santiago; Mesa, José de y Gisbert, Teresa (1986). Arte Iberoamericano desde la colonización a la independencia. Segunda parte. Volumen XXIX, Madrid: EspasaCalpe. S.A.

Vargas Ugarte SI, Rubén (1963). Los Jesuitas del Perú y el Arte. Lima. -- (1968). Ensayo de un diccionario de artífices de la América meridional. BurgosEspaña.

Vásquez González, José M. (2011). Huamanga: Historia, Tradición y Cultura, Ayacucho.

Velarde, Héctor (1978). Arquitectura peruana. 3ra edición. Ediciones "Studium". Lima.

Wuffarden, Luis Eduardo (2002). "Iglesia y Colegio de la Compañía, Ayacucho (Huamanga) Perú". En: Fundaciones jesuiticas en Iberoamérica. De la edición: Fundación Iberdrola. 